IFN Working Paper No. 1053, 2015

\title{
Does Social Trust Speed up Reforms? The Case of Central-Bank Independence
}

Niclas Berggren, Sven-Olov Daunfeldt and Jörgen Hellström 


\title{
Does social trust speed up reforms? The case of central-bank independence
}

\author{
Niclas Berggren ${ }^{\mathrm{a}, \mathrm{b}, *}$, Sven-Olov Daunfeldt ${ }^{\mathrm{c}, \mathrm{d}}$, Jörgen Hellström ${ }^{\mathrm{e}}$ \\ ${ }^{a}$ Research Institute of Industrial Economics (IFN), Stockholm, Sweden \\ ${ }^{b}$ Department of Institutional Economics, University of Economics in Prague, Czech Republic \\ ${ }^{c}$ HUI Research, SE-103 29 Stockholm, Sweden \\ ${ }^{d}$ Department of Economics, Dalarna University, Borlänge, Sweden \\ ${ }^{e}$ Umeå School of Business and Economics, Umeå University, Umeå, Sweden
}

\begin{abstract}
A B S T R A C T
Many countries have undertaken central-bank independence reforms, but the years of implementation differ. What explains such differences in timing? This is of interest more broadly, as it sheds light on factors that matter for the speed at which economic reforms come about. We study a rich set of potential determinants, both economic and political, but put special focus on a cultural factor, social trust. We find empirical support for an inverse u-shape: Countries with low and high social trust implemented their reforms earlier than countries with intermediate levels. We make use of two factors to explain this pattern: the need to undertake reform (which is more urgent in countries with low social trust) and the ability to undertake reform (which is greater in countries with high social trust).
\end{abstract}

JEL classification:

E52, E58, P48, Z13.

Keywords:

Central banks, Independence, Social trust, Inflation, Monetary policy, Reform

\footnotetext{
* Corresponding author at: Research Institute of Industrial Economics (IFN), P.O. Box 55655, SE-102 15

Stockholm, Sweden. Tel.: +46 866545 20; fax: +46 86654599.

E-mail address: niclas.berggren@ifn.se (N. Berggren).
} 


\section{Introduction}

Central-bank independence (CBI) has been increased in many countries since the late 1980s (Cukierman, 2008; Arnone et al., 2009). The underlying motivation of the reforms leading up to this greater independence is a belief that they contribute to lower inflation rates by limiting the discretionary power of politicians, who have an incentive to use monetary policy for electoral gain (Kydland and Prescott, 1977; Rogoff 1985). There are, indeed, indications that CBI has been successful in this regard (Brumm, 2006; Acemoglu et al., 2008; Klomp and de Haan, 2010). However, the year of implementation of these reforms differs between countries. What explains such differences in timing? Knowing the answer to this question is important, since it helps clarify which factors that facilitate or stall important economic reforms.

Therefore, we analyse potential determinants of how long it takes for CBI reforms to come about. We include political and economic factors - but also cultural variables, with special attention being paid to social trust, measured as the share of a population that thinks that people in general can be trusted. An increasing number of studies find that cultural factors, not least social trust, help explain economic, political and social outcomes (Alesina and Giuliano 2013; Algan and Cahuc 2013).

In particular, we present reasons for expecting an inverse u-shaped relationship between social trust and the time it takes for CBI reform to be undertaken. The idea is that low trust entails a strong need for reform, which will induce policymakers to try to undertake it more swiftly, while high trust entails a strong ability to undertake reform, which will facilitate for policymakers to agree on it and to push it through. These two factors explain why low and high trust can be expected to be associated with relatively quick policy reform. At intermediate trust levels, however, there is neither need nor ability strong enough to speed up the reform process, making it slower.

Our empirical analysis supports such a pattern, for our full sample as well as for democracies and autocracies separately. Interestingly, for democracies, the inverse u shape is skewed, such that it is almost linear. This suggests that the predominant relationship is one of higher social trust being associated with faster CBI reform in this subsample. In addition, we find that some factors, in addition to trust, tend to speed up reforms: inflation, democracy, change to democracy, membership in the European System of Central Banks (ESCB), number of CBI reforms in countries with which there is economic cooperation, uncertainty avoidance and masculinity. Some other variables, on the contrary, seem to prolong the time to reform: unemployment and IMF credits. 
To our knowledge, this is the first study to look at cultural, political and economic factors as potential explanations of how fast economic reforms are implemented. Alesina et al. (2006) include economic and political variables but not cultural ones; they find that reforms are more rapidly adopted after crises, when new governments take office and when strong presidents or clear legislative majorities are present. Otherwise, previous studies do not primarily look at the speed of reforms but at factors that might affect reforms coming about or the scope of reforms. For example, Heinemann and Tanz (2008) study how social trust relates to market-oriented institutional reforms, and they find evidence that it promotes such reforms in three areas: government size, the legal system and the regulation of private companies and the labour market. Pitlik and Wirth (2003) report that inflation and growth crises, as well as democracy and a divided system of government, are positively related to liberalization. Similarly, Pitlik (2008) shows that a bad growth performance is conducive to liberalizing reforms in democracies but not in autocracies; and Giuliano et al. (2013) find a positive effect of democracy on the adoption of economic reforms. Daunfeldt et al. (2013) find that CBI reform was more probable in non-OECD countries if there had been high and variable inflation in the past and if the politicians faced a high probability of being replaced.

With this as the background, we first outline our theoretical idea of the relationship between social trust and reform speed; we then present our data and empirical methodology; after which the results, and our interpretation, are introduced.

\section{Social trust and central-bank independence reform}

The basic starting point is a situation with "too high inflation", as perceived by central political decision-makers. They then ponder how to reduce it, and if they (or their advisors) have read their Kydland and Prescott (1977) and Rogoff (1985), they realise that the situation is the result of the institutional setting within which monetary policy has been conducted and the incentives this setting has entailed. The question is how a change in this setting that results in lower inflation can be achieved and, when a solution (CBI reform) has been identified, how it can be brought about in a quick manner. It is here that social trust becomes important, for explaining the speed with which CBI reform comes about.

\subsection{Two relevant factors: need and ability}

We propose, primarily inspired by Heinemann and Tanz (2008) and Berggren et al. 
(2014), that two factors are relevant: the need and the ability to undertake reform.

The need for CBI reform is greater the lower the level of social trust. The reason is that with little trust, the underlying problem of the situation that gave rise to high inflation - which is a credibility or lack-of-trust problem - is worse. Plausibly then, inflation is also higher. A low-inflation monetary policy is not credible if people and financial actors do not trust the politicians to adhere to stated goals of keeping inflation low, and the well-known result with high inflation ensues. This makes it more important to change the institutional setting for monetary policy such that a decision-making instance that will not face incentives to raise inflation gets more power. This implies a more independent central bank. However, if people trust others, including policymakers, plausibly because of displayed trustworthiness, the lackof-trust problem is smaller and inflation arguably lower (albeit still possibly perceived to be too high). In that case, the need for CBI is smaller. If the need for reform is perceived to be high, then actors will also make stronger efforts to make it come about, and the more probable it is that it, indeed, also comes about fast. ${ }^{1}$ To this one can add the idea of Funke (1993), that if reform policies are not perceived as credible, one needs to implement them quickly, both to overcome resistance and to allow them to yield beneficial outcomes reasonably soon.

The ability to undertake CBI reform is greater the higher the level of social trust. This is because trust helps remove obstacles to reforms coming about, among other things in the following ways. First, trust makes it easier to dissemble expert information about the longterm benefits of reforms: people will be more willing to accept such information, from policymakers and the media, if the senders are perceived to be trustworthy (Boix and Posner, 1998). Second, interest groups can block reform if they think that they can gain by opposing it, but high trust reduces suspicion and enhances cooperation among groups, making the blocking of reforms less probable. ${ }^{2}$ Third, compensation schemes are more credible in a setting with high trust, which makes it easier for those in society who think they will lose out on reforms to accept them, given compensation promises. Trust is also related to pro-social preferences (Fehr, 2009), and therefore even people who think they will lose from reforms can be expected to be more willing to accept them even without compensation schemes, if they believe that the reforms will result in good social consequences. This can make politicians in high-trust contexts bold in proposing reforms, as they consider the risk of

\footnotetext{
${ }^{1}$ The clearest illustrations of this logic appear after crises: then the need for reform is often abundantly clear, and reform then also tend to come about rather quickly. On the link between crises and reforms, see, e.g., Drazen and Grilli (1993), Drazen and Easterly (2001), Pitlik and Wirth (2003) and Campos et al. (2010).

${ }^{2}$ On interest-group blocking of reforms, see Alesina and Drazen (1991) and Fernandez and Rodrik (1991).
} 
electoral punishment relatively small. Fourth, initiators of CBI reforms in a country with high trust will not expect their political opponents to exploit a reform process for short-term gain to any great extent; and they will also expect bureaucrats, not least in the central bank, to behave well and follow their intentions with the reform, once it is in place. ${ }^{3}$ All of these factors indicate that trust increases the ability to undertake reform, and the higher the ability to undertake reform, the sooner it comes about, all else equal.

When putting these two factors, need and ability, together, we get a relationship between social trust and the time it takes for a CBI reform to come about in the form of an inverse u-shape. At low levels of social trust, the need for reform is urgent, and as decisionmakers therefore work hard to bring about reform, the time it takes is relatively short. At high levels of social trust, the ability for reform is high, and therefore the time for reform to become about is relatively short. At intermediate levels of social trust, neither need nor ability is very high, which implies a longer time before reform happens.

\subsection{The way in which social trust matters}

We see low or high social trust as helping but not solely causing CBI reform to come about. If low or high social trust was sufficient, it could not easily be explained why countries with similar trust levels have had similar CBI reforms at different points in time. Rather, according to our understanding, social trust affects some but not all necessary (and jointly sufficient) factors required for CBI reform to occur. This means that low or high social trust (compared to intermediate levels) makes it more likely that all necessary conditions are met, and that reform comes about, earlier rather than later, but it alone does not suffice.

Following Berggren et al. (2014), we suggest these necessary conditions for reform implementation: that certain ideas have emerged and have been accepted (the identification by academic economists of the time inconsistency problem), that there is a perception of a problem that needs to be solved (high inflation rates, the political dependence of central banks) and that some individuals are willing to lead the initiation of a reform process. Social trust arguably affects the latter two of these conditions (by affecting the perceived need for and the ability to undertake reform), but it does not solely cause these necessary conditions to be met and it does not affect the first necessary condition. The time it takes for CBI reform to

\footnotetext{
${ }^{3}$ Leibrecht and Pitlik (2014) show that social trust is positively related to economic liberalization, and the more so the stronger the institutional and political constraints on the executive are. That is, when it should be especially difficult to agree on reforms, due to institutional hinders and political polarization, trust is especially valuable in making reforms come about.
} 
appear can therefore vary between countries, even though trust levels are quite stable over time and even though they are sometimes similar between countries.

\section{Data}

Based on data in Daunfeldt et al. (2013), collected through a questionnaire to central banks worldwide, we know when major CBI reforms occurred. Hence, our dependent variable is the number of years from 1980 until CBI reform took place (2005 at the latest). This variable thus takes a low (high) value for countries implementing CBI reforms relatively early (late).

Our explanatory variable of main interest is social trust, the share of the population that answers "yes" to the first part of the question: "In general, do you think most people can be trusted or can’t you be too careful?” Like Bjørnskov (2007), we use the average of all available observations in the World Values Survey, LatinoBarómetro, the AfroBarometer, the Asian and East Asia Barometers, and the Danish Social Capital Project; the idea is that averages reduce the risk of letting atypical data of individual years matter.

We also use a set of economic and political control variables, based on previous studies: inflation (IMF, 2011); unemployment (ILO, 2011); GDP per capita and the use of credits from the IMF (World Bank, 2011); political fragmentation in parliament and whether the country is a federation or not (Lundell and Karvonen, 2003); the number of coups (Marshall and Marshall, 2007); the quality of government (ICRG, 2008); a democracy dummy (Cheibub et al., 2010); change to democracy (in the preceding decade) (Cheibub et al., 2010); CBI reforms in economic cooperation (to capture peer effects), i.e., the number of countries with preceding CBI reforms in the organization of which the country is a member (of the European Union, the African Economic Community, the Asia-Pacific Economic Cooperation or the Latin American Free Trade Association) prior to reform in the own country (Daunfeldt et al., 2013); pre-reform CBI (Cukierman et al., 1992); dummy for members of the ESCB (European System of Central Banks); and three cultural variables: power distance (the extent to which inhabitants in a country accept that power is distributed unequally within a society), uncertainty avoidance (tolerance of uncertainty) and masculinity (the extent to which individuals in a country tend to endorse goals usually more popular among men) (De Jong, 2002). These explanatory variables are measured as the average of the values for the ten-year period preceding CBI reforms (different time periods in different countries).

Several of these variables have missing values, and since there is a great risk that this 
introduces bias and affects the representativeness of the sample (from list-wise deletion of cases with missing observations), we have created a larger sample through multiple imputation (Graham et al., 2003). The multiple imputation approach produces unbiased parameter estimates that reflect the uncertainty associated with missing observations and is robust to violations of assumptions in the underlying imputation model. We use five imputed datasets. The empirical analysis is performed on each of these datasets, and the estimation results for each are later combined (Rubin, 1987).

The sample includes 149 countries observed annually over the period 1980 to 2005 . Descriptive statistics are given in Table 1.

[Table 1 about here]

\section{Empirical analysis}

To analyze the time it takes for CBI reforms to be implemented, with particular focus on social trust, we perform a duration analysis (see, e.g., Cameron and Trivedi, 2005). As mentioned, our dependent variable is the number of years it takes from 1980 for CBI to be implemented. All countries enter the sample in 1980, the mean time until CBI reform is 21.5 years (median 23 years) and the number of countries implementing CBI reforms is 90 . The data are right censored at 26 years (for the 59 countries without a CBI reform).

In Fig. 1 we display the unconditional Kaplan-Meier survivor (left) and the smoothed hazard functions (right). ${ }^{4}$ The survival function indicates that implementation of CBI reforms began after ten years (the sample starts in 1980) and that the probability of observing no CBI reforms in the population declined each following year, with the largest drop after 19 years, indicating that CBI reforms were becoming more likely to occur. The probability that an average country implements a CBI reform at $t$ (given no previous implementation) increased until 2002 (22 years from 1980) and then declined, as indicated by the hazard function.

[Fig. 1 about here]

\footnotetext{
${ }^{4}$ The Kaplan-Meier estimate is a nonparametric estimate of the true underlying survival function for the population showing the probability that a CBI reform is not implemented before a specific time, i.e. that the state of "no CBI" survives beyond a specified time (note here that failure means the implementation of a CBI reform, while survival correspond to no CBI reform). The hazard function displays the probability of a CBI reform for an average country at $t$, given that it has not been implemented up until $t$.
} 
To model the time it takes until a CBI reform is undertaken we utilise a parametric approach, since it produces more efficient estimates conditional on a correct distributional assumption. ${ }^{5}$ In Table 2 we report the estimated Akaike and Bayesian information criteria for models based on the generalized gamma, Weibull, log-logistic, log-normal, gompertz and the exponential distributions, for both a linear and non-linear specification of our trust variable (including all other control variables in all specifications).

\section{[Table 2 about here]}

As can be seen, based upon both information criteria, the generalized gamma distribution is preferable for all models (closely followed by the log-normal for the non-linear specification). The generalized gamma model has a density given by

$f(t)=\frac{\lambda p(\lambda t)^{p \kappa-1} e^{-(\lambda t)^{p}}}{\Gamma(\kappa)}$

where $\lambda=\exp (X \beta)$ and $(p, \kappa)$ are two shape parameters allowing for a flexible hazard rate. ${ }^{6}$

In Table 3 estimation results for a number of gamma distributed models are displayed with trust entering in a linear fashion.

[Table 3 about here]

All models imply a negative significant effect, at the 5 percent level, from trust on duration until reform, i.e., a higher trust level shortens the time until a CBI reform is implemented. To get a feeling for the magnitude of the estimates, we calculate marginal effects in the following way:

\footnotetext{
${ }^{5}$ We have also considered non-parametric Cox proportional hazard models. Results from these models with regard to our trust variable were in general similar to those reported here, although with somewhat lower significance levels.

${ }^{6}$ A nice feature of the generalized gamma model is that it nests a number of the other parametric models as special cases: Weibull $(\kappa=1)$, exponential ( $p=\kappa=1)$, log-normal $(\kappa=0)$ and the standard gamma $(p=1)$. Testing these nested model alternatives, i.e. testing whether parameter restrictions of the alternative models hold, confirms our conclusion that a generalized gamma model is preferable for our considered sample. Henceforth, our analysis is therefore reported for specifications based on the generalized gamma distribution.
} 
percentage change in the time it takes for CBI reform to come about $=100 \times\left[e^{\widehat{\beta}_{k} \delta}-1\right]$

where $\delta$ is the change in the covariate $X_{k}$. The estimate for the trust variable indicates that a increase in trust of 20 percentage points (e.g., from the level of France, 0.22, to that of the U.S., 0.42), all else equal, would decrease the time until reform by 8.8 percent. That is, if France had had the trust level of the U.S., all else equal, the CBI reform would have been implemented about one year earlier.

So far, we have modeled trust in a linear fashion, but as proposed in section 2, trust may stand in a non-linear relation to the time until reform. To investigate possible non-linear effects, we first consider adding a quadratic trust term. ${ }^{7}$ In Table 4, model 5 , the results imply an inverse u shape, but the positive-sloping segment is insignificant. ${ }^{8}$

However, we prefer another way of considering non-linearity: using a restricted cubic spline. This allows for a more flexible non-linear form than the mere addition of a quadratic trust term. With a restricted cubic spline, a continuous smooth function for trust is obtained: linear before the first knot, piecewise cubic polynomial between adjacent knots and linear again after the last knot. Modeling the non-linear effect of trust with a restricted cubic spline with three knots at the 10, 50 and 90 percentiles of the trust variable confirm the inverse $u$ shape as well as its statistical significance - see model 6 in Table $4 .^{9}$

[Table 4 about here]

In Fig. 2 the predicted time until reform (based on model 6, with trust modeled as a restricted cubic spline) is displayed, varying over the social trust variable, with a 95-percent confidence interval indicated by the shaded area and with other explanatory variables at their mean. As can be seen, the time until reform varies from about 22 years at an intermediate trust level to a little more than 16 years at the highest trust level.

\footnotetext{
${ }^{7}$ Note that the control variables of model 4 in Table 3 are used throughout the ensuing analysis. The results for these are not listed here but are qualitatively similar to the ones reported in Table 3.

${ }^{8}$ However, in a model based on the log-normal distribution both trust terms, and the full inverse u relationship, are significant - see model 9 in Table 4.

${ }^{9}$ To check for sensitivity, we perform the same analysis using the log-normal distribution in model 10 in fig. 4, with the same qualitative results.
} 
[Fig. 2 about here]

In Fig. 3, the corresponding marginal effects varying with social trust are displayed, for an increase in trust of 10 percentage points, all else equal. Thus, it shows the marginal effect, i.e., the predicted change in time until reform of such a change in trust for different values of trust. The 95-percent confidence levels are indicated by the shaded area. For example, the figure implies that if Switzerland (with a trust level of 0.44) experienced an increase of trust with 10 percentage points, it would implement a CBI reform about 1.5 years earlier; and that if Poland (with a trust level of 0.21) experienced the same change in trust, it would implement a CBI reform about 1 year later.

[Fig. 3 about here]

In Table 4 we also run separate models for democracies and non-democracies (models 7 and 8). We make this division as the political decision-making process arguably differs between the two country groups, which might affect the way in which trust affects the speed of reform. For example, we would expect the ability part of our theory to play a more important role in democracies, since collective decision-making involves more groups of actors and is more fractionalized (cf. Boix and Posner, 1998). We would also expect the need part of our theory to matter more in autocracies, since trust is lower in such countries, which implies that formal reforms are more important to achieve a certain goal. Since the sample sizes are reduced by making this division, models based on the relatively complex generalized gamma distribution turn out not to converge. However, results from models based on the lognormal distribution (second best for non-linear specifications, according to Table 2) confirm the inverse u shape for both democracies and non-democracies.

In Fig. 4, the predicted time until reform (in years) for the separate samples of democracies (left) and non-democracies (right) (based on model 8 and 9 from Table 4, modeling trust as a restricted cubic spline) are displayed over the social trust variable, with the 95-percent confidence indicated by the shaded area and with other explanatory variables at their mean.

[Fig. 4 about here] 
While the inverse u shape is obtained for both samples, the negative slope dominates for the sample of democracies (for those with a trust level a bit above 0.20), implying that here, higher trust implies faster CBI reform. Reform comes about quickly in these countries because of a strong ability to agree on the implementation of reform, an ability that increases in trust. For autocracies, with generally low trust levels, the need for reform is what drives the results.

In Fig. 5, the corresponding marginal effects (in years) for democracies (left) and nondemocracies (right) for an increase in trust of 10 percentage points are displayed, all else equal.

[Fig. 5 about here]

To exemplify, for the sample of democracies these results imply that if the Netherlands (with a trust value of 0.55 ) increased its trust by 10 percentage points, it would, all else equal, be likely to implement a CBI reform about 1.5 years earlier. For non-democracies the results imply that Morocco (with a trust level of 0.18 ) would be likely to implement a CBI reform almost 3 years later if its trust level increased by 10 percentage points. Notable, marginal effects are significantly different from zero for social trust levels above about 0.24 for democracies and for trust levels below about 0.26 for non-democracies.

As for other explanatory variables, it turns out that several are related to the speed of reform. The results for our main model (model 6 in Table 4, unreported here, but available upon request) are similar to those reported for model 4 in Table 3 and indicate that a relatively higher inflation, being or becoming a democracy in the previous 10 year period, being a ESCB member, having a larger number of CBI-reforms in countries with which there is economic cooperation, being characterized by uncertainty avoidance (the tolerance of uncertainty found in people) and masculinity (the extent to which individuals in a country tend to endorse goals usually more popular among men), all shorten the duration to CBIreform for an average country. In contrast, a relatively higher unemployment rate and IMF credits increase the duration.

To comment on a few of these, a 10 percentage point higher past inflation rate shortens the duration to reform with about 7 months. High historical inflation, thus, seems to create stronger preferences for implementing reforms in order to achieve credibility for a lowinflation goal, supporting Hayo's (1998) claim that CBI is related to an historical feedback 
process. Democracies on average implement CBI reforms 3.6 years earlier than nondemocracies and countries that changed their ruling system to a democracy in the previous 10-year period implemented CBI-reforms about 4 years earlier (compared with both other democracies and non-democracies). Countries that are members of the ESCB are on average 4.3 years faster with their CBI-reforms than non-membership countries. These latter results clearly illustrate that the institutional framework matters for the speed of reform. As for unemployment, a higher past rate of 10 percentage points relates to a delay with 1.5 months. We suggest that this follows from politicians believing that CBI reforms will entail lower inflation and from expecting, due to simple Phillips-curve considerations, that this will worsen the unemployment problem (and their ability to combat it in the future).

In contrast to these results, more IMF credits appear to increase the time it takes for a CBI reform to come about, which is somewhat unexpected. Maxfield (1997) suggests that CBI reforms are more likely to be implemented in high-debt developed countries, since they want to signal creditworthiness to foreign investors and IMF in order to get more funds. This would imply earlier reforms in high-debt countries. This theory is thus not supported by our results.

To test the sensitivity of our results towards using multiple imputation to replace missing observations we also present results, in models 9 and 10 in Table 4, for the two different non-linear trust specifications (quadratic trust and restricted cubic splines) where traditional mean imputation was used instead. Reassuringly, the results confirm the previously found inverse u shape for social trust.

Given that ESCB membership required monetary stability one may view the ESCB membership variable as potentially endogenous. To test whether our results are affected by the inclusion of this variable, we have re-run our regressions excluding the ESCB membership variable. Results (available upon request) indicate that the results hold also when not conditioning on being an ESCB member.

Finally, we have also tested to what extent our results are affected by extreme observations by re-estimating models on a sample excluding the top and bottom 5 percentiles of the social trust distribution. The results remain unchanged.

\section{Concluding remarks}

It comes with the job for politicians to present reform proposals in order to better achieve desired outcomes. But it is one thing to want a reform, another to see it become 
reality. While some reforms are implemented quickly, others take a long time and may never see the light of day. In this paper, we try to explain the speed of reforms. What factors may shed light on how fast reform comes about? We look at economic and political factors but especially highlight a cultural variable, social trust, as an explanatory factor. Do reforms come about faster depending on whether trust is high, low or intermediate?

We try to answer this question by looking at a particular kind of reform, to increase central-bank independence in order to increase chances for credible low-inflation policies. We argue, on theoretical grounds, that social trust should matter for bringing about CBI, by affecting both the ability and the perceived need to undertake reforms. This implies an inverse u-shaped relationship, such that both low and high trust levels are associated with earlier reforms. In the former case, the need for reform is sufficiently high to bring about political action and quick reform; in the latter case, the ability to undertake reform, by mitigation of various obstacles, is sufficiently high to bring about fast reform. In the intermediate case, neither need nor ability is strong enough for trust to speed up reform, and the time it takes is consequently longer.

Our empirical investigation, comprising a sample of 149 countries, indicates that the inverse u shape indeed obtains. CBI reform comes about more quickly in countries with low and in countries with high trust, but it takes longer time in the countries in between. In countries where about 25 percent think that others can be trusted (the intermediate case), it took about 22 years from 1980 for CBI reform to come about. The corresponding figure for countries with really low trust was around 19 years and for countries with really high trust about 17 years - in the latter case a five-year difference.

The inverse u shape is found for both democracies and autocracies when studying them separately. However, the shape of the curve for democracies is heavily skewed to the right, implying primarily that high trust speeds up reforms in such countries. Presumably, this is because the political process comes to agreement much faster in the presence of central actors trusting each other. For the autocracies, the effect of trust is such that low levels are related to faster reform, arguably because in such low-trust settings, the need for reform is especially great for a goal of credible low inflation to be obtained.

What we find particularly interesting is that in addition to "traditional" explanatory factors, e.g. previous experiences with inflation, the unemployment rate, membership in the European System of Central Banks and in organizations within which other countries had undertaken reforms before, a cultural factor is at least as central, and often more important (quantitatively), for explaining the time it takes until a reform is undertaken. This points at the 
importance of incorporating social trust and other cultural factors in future studies of economic reforms of various kinds.

\section{Acknowledgments}

The authors wish to thank Christian Bjørnskov for very helpful advice, participants in the Australasian Public Choice Society conference in Singapore, the WINIR conference in London and the WWWforEurope conference at Mendel University in Brno for good comments and Johan and Jakob Söderbergs stiftelse (Berggren), the Marianne and Marcus Wallenberg Foundation (Berggren) and the Swedish Research Council (Berggren) for financial support.

\section{References}

Acemoglu, D., Johnson, S., Querubín, P., Robinson, J.A., 2008. When does policy reform work? The case of central bank independence. Brookings Papers on Economic Activity 1 (Spring), 351-418.

Alesina, A., Ardagna, S., Trebbi, F., 2006. Who adjusts and when? The political economy of reforms. IMF Staff Papers 53, 1-29.

Alesina, A., Drazen, A., 1991. Why are stabilizations delayed? American Economic Review 81 (5), 1170-1188. Alesina, A., Giuliano, P., 2013. Culture and institutions. NBER Working Paper No. 19750. National Bureau of Economic Research, Cambridge, MA.

Algan, Y., Cahuc, P., 2013. Trust, growth, and well-being: new evidence and policy implications. In: Aghion, P., Durlauf, S.N. (Eds.). Handbook of Economic Growth: Volume 2A. Elsevier, Amsterdam, pp. 49-120.

Arnone, M., Laurens, B.J., Segalotto, J.-F., Sommer, B., 2009. Central bank autonomy: lessons from global trends. IMF Staff Papers 56, 263-296.

Berggren, N., Daunfeldt, S.-O., Hellström, J., 2014. Social trust and central-bank independence. European Journal of Political Economy, forthcoming.

Bjørnskov, C., 2007. Determinants of generalized trust: a cross-country comparison. Public Choice 130 (1-2), 121.

Boix, C., Posner, D.N., (1998). Social capital: explaining its origin and effects on government performance. British Journal of Political Science 28 (4), 686-693.

Brumm, H.J., 2006. The effect of central bank independence on inflation in developing countries. Economics Letters 90 (2), 189-193.

Cameron, C., Trivedi, P.K., 2005. Microeconometrics: methods and applications. Cambridge University Press, Cambridge.

Campos, N.F., Hsiao, C., Nugent, J.B., 2010. Crisis, what crisis? New evidence on the relative roles of political and economic crises in begetting reforms. Journal of Development Economics 46 (10), 1670-1691. 
Cheibub, J., Gandhi, J., Vreeland, J., 2010. Democracy and dictatorship revisited. Public Choice 143 (1-2), 67101.

Cukierman, A., Webb, S.B., Neyapti, B., 1992. Measuring the independence of central banks and its effects on policy outcomes. World Bank Economic Review 6 (3), 353-398.

Cukierman, A., 2008. Central bank independence and monetary policymaking institutions - past, present and future. European Journal of Political Economy 24 (4), 722-736.

Daunfeldt, S.-O., Hellström, J., Landström, M., 2013. Why do politicians implement central bank independence reforms? Atlantic Economic Journal 41 (4), 427-438.

De Jong, E. 2002. Why are price stability and statutory independence of central banks negatively correlated? The role of culture. European Journal of Political Economy 18 (4), 675-694.

Drazen, A., Easterly, W., 2001. Do crises induce reform? Simple empirical tests of conventional wisdom. Economics and Politics 13 (2), 129-157.

Drazen, A., Grilli, V., 1993. The benefit of crises for economic reforms. American Economic Review 83 (3), 598-607.

Fehr, E., 2009. On the economics and biology of trust. Journal of the European Economic Association 7 (2-3), 235-266.

Fernandez, R., Rodrik, D., 1991. Resistance to reform: status quo bias in the presence of individual-specific uncertainty. American Economic Review 81 (5), 1146-1155.

Funke, N., 1993. Timing and sequencing of reforms: competing views and the role of credibility. Kyklos 46 (3), 337-362.

Giuliano, P., Mishra, P., Spilimbergo, A., 2013. Democracy and reforms: evidence from a new dataset. American Economic Journal: Macroeconomics 5 (4), 179-204.

Graham, J.W., Cumsille, P.E., Elek-Fisk, E., 2003. Methods for handling missing data. In: Schinka, J.A., Velicer, W.F. (Eds.), Research Methods in Psychology: Volume 2 of Handbook of Psychology. John Wiley \& Sons, New York, NY, pp. 109-141.

Hayo, B., 1998. Inflation culture, central bank independence and price stability. European Journal of Political Economy 14 (2), 241-263.

Heinemann, F., Tanz, B., 2008. The impact of trust on reforms. Journal of Economic Policy Reform 11 (3), 173185.

ICRG, 2008. International Country Risk Guide. The PRS Group, Syracuse, NY.

ILO, 2011. LABORSTA database at http://laborsta.ilo.org (accessed 12.04.2013).

IMF, 2011. International financial statistics database at http://elibrary-data.imf.org (accessed 10.03.2013).

Klomp, J., de Haan, J., 2010. Inflation and central bank independence: a meta-regression analysis. Journal of Economic Surveys 24 (4), 593-621.

Kydland, F.E., Prescott, E.C., 1977. Rules rather than discretion: the inconsistency of optimal plans. Journal of Political Economy 85 (3), 473-490.

Leibrecht, M., Pitlik, H., 2014. Generalised trust, institutional and political constraints on the executive and deregulation of markets. Working paper No. 481, WIFO, Vienna, Austria.

Lundell, K., Karvonen, L., 2003. A comparative data set on political institutions. Occasional Paper No. 28. Department of Political Science, Åbo Akademi, Åbo, Finland. 
Marshall, M.G., Marshall, D.R., 2010. Coup d'état events 1946-2010 at http://www.systemicpeace.org/inscr/CSPCoupsCodebook2010.pdf (accessed 18.05.2013).

Maxfield, S., 1997. Gatekeepers of growth: The international political economy of central banking in developing countries. Princeton University Press, Princeton, NJ.

Pitlik, H., 2008. The impact of growth performance and political regime type on economic policy liberalization. Kyklos 61 (2), 258-278.

Pitlik, H., Wirth, S., 2003. Do crises promote the extent of economic liberalization? An empirical test. European Journal of Political Economy, 19 (3), 565-581.

Rogoff, K., 1985. The optimal degree of commitment to an intermediate monetary target. Quarterly Journal of Economics 110 (4), 1169-1190.

Rubin, D.B., 1987. Multiple Imputation for Nonresponse in Surveys. John Wiley \& Sons, New York, NY.

World Bank, 2005. Economic Growth in the 1990s: Learning from a Decade of Reform. World Bank, Washington, DC. 
Table 1. Descriptive statistics.

\begin{tabular}{lcccccc}
\hline & Mean & S.d. & Median & Minimum & Maximum & Share \\
\hline Time to CBI reform since & 19.59 & 4.23 & 22 & 9 & 23 & 0 \\
1980 (No. of years) & 0.24 & 0.12 & 0.22 & 0.04 & 0.68 & $22 \%$ \\
Social trust & 0.35 & 0.12 & 0.35 & 0.09 & 0.82 & $51 \%$ \\
Pre-reform CBI & 0.28 & 0.41 & 0.12 & -0.00 & 2.43 & $12 \%$ \\
Inflation & 7994 & 8118 & 5198 & 298 & 37071 & $9 \%$ \\
GDP per capita & 8.68 & 5.16 & 9.46 & 0.35 & 31.20 & $55 \%$ \\
Unemployment & 0.44 & 0.49 & 0 & 0 & 1 & $46 \%$ \\
Federation & 0.23 & 0.49 & 0.02 & 0 & 2.67 & $1 \%$ \\
IMF credits & 5934 & 1444 & 5935 & 0 & 9554 & $42 \%$ \\
Party fragmentation & 0.04 & 0.09 & 0 & 0 & 0.54 & $17 \%$ \\
Coups & 0.60 & 0.49 & 1 & 0 & 1 & $0 \%$ \\
Democracy & 0.17 & 0.37 & 0 & 0 & 1 & $0 \%$ \\
Change in democracy & 0.19 & 0.43 & 0 & 0 & 1 & $0 \%$ \\
ESCB membership & 0.60 & 0.20 & 0.57 & 0.17 & 1 & $32 \%$ \\
Quality of government & 3.42 & 4.63 & 0 & 0 & 18 & $0 \%$ \\
CBI reforms in economic & 0.59 & 0.15 & 0.59 & 0.11 & 1.04 & $55 \%$ \\
cooperation & 0.68 & 0.16 & 0.68 & 0.08 & 1.12 & $55 \%$ \\
Power distance & 0.49 & 0.13 & 0.49 & 0.05 & 1.1 & $55 \%$ \\
Uncertainty avoidance & 149 & & & & & \\
Maculinity & Number of countries & 0.49 & & \\
\hline
\end{tabular}

Notes: The values for the explanatory variables correspond to the average value over ten years preceding the implementation of major CBI reforms in each country. Share refers to the proportion of observations, in relation to the total, that are missing and have been replaced with multiple imputation. 
Table 2. Akaike and Bayesian information criteria for different model and distributional specifications.

\begin{tabular}{lcccc}
\hline & Akaike & Bayesian & Akaike & Bayesian \\
\cline { 2 - 5 } Distribution & Linear trust & Linear trust & Non-linear trust & Non-linear trust \\
\hline Generalized & & & & \\
gamma & 136.22 & 139.23 & 134.49 & 137.49 \\
Weibull & 137.17 & 140.17 & 136.32 & 139.32 \\
Loglogistic & 138.38 & 141.38 & 136.41 & 139.41 \\
Lognormal & 138.58 & 141.59 & 134.72 & 137.72 \\
Gompertz & 151.15 & 154.16 & 150.28 & 153.28 \\
Exponential & 278.84 & 284.85 & 278.34 & 284.36 \\
\hline
\end{tabular}


Table 3. Duration analysis of determinants of time until implementation of CBI reform - linear trust

\begin{tabular}{|c|c|c|c|c|}
\hline & Model 1 & Model 2 & Model 3 & Model 4 \\
\hline \multirow[t]{2}{*}{ Social trust } & $-0.14 * *$ & $-0.16^{* *}$ & $-0.34 * *$ & $-0.46 * *$ \\
\hline & $(0.00)$ & $(0.03)$ & $(0.01)$ & $(0.10)$ \\
\hline \multirow[t]{2}{*}{ Pre-reform CBI } & -0.04 & -0.07 & -0.10 & -0.02 \\
\hline & $(0.21)$ & $(0.17)$ & $(0.17)$ & $(0.29)$ \\
\hline \multirow[t]{2}{*}{ Inflation } & $-0.27 * *$ & $-0.27 * *$ & $-0.25 * *$ & $-0.26 * *$ \\
\hline & $(0.09)$ & $(0.09)$ & $(0.11)$ & $(0.09)$ \\
\hline \multirow[t]{2}{*}{ GDP per capita } & 0.07 & 0.06 & 0.06 & 0.08 \\
\hline & $(0.07)$ & $(0.08)$ & $(0.09)$ & $(0.08)$ \\
\hline \multirow[t]{2}{*}{ Unemployment } & $0.09 * *$ & $0.08 * *$ & $0.06 *$ & $0.04 * *$ \\
\hline & $(0.03)$ & $(0.01)$ & $(0.03)$ & $(0.01)$ \\
\hline \multirow[t]{2}{*}{ Federation } & 0.03 & 0.03 & 0.04 & 0.04 \\
\hline & $(0.05)$ & $(0.06)$ & $(0.05)$ & $(0.05)$ \\
\hline \multirow[t]{2}{*}{ IMF credits } & $0.14^{* *}$ & $0.15 * *$ & $0.13 *$ & $0.14^{* *}$ \\
\hline & $(0.07)$ & $(0.07)$ & $(0.07)$ & $(0.07)$ \\
\hline \multirow[t]{2}{*}{ Party fragmentation } & -0.12 & -0.13 & -0.07 & -0.12 \\
\hline & $(0.37)$ & $(0.34)$ & $(0.38)$ & $(0.35)$ \\
\hline \multirow[t]{2}{*}{ Coups } & 0.02 & 0.02 & 0.02 & 0.01 \\
\hline & $(0.03)$ & $(0.03)$ & $(0.02)$ & $(0.04)$ \\
\hline \multirow[t]{2}{*}{ Democracy } & $-0.18 * *$ & $-0.18 * *$ & $-0.16 * *$ & $-0.16 * *$ \\
\hline & $(0.01)$ & $(0.01)$ & $(0.01)$ & $(0.00)$ \\
\hline \multirow[t]{2}{*}{ Change to democracy } & $-0.23 * *$ & $-0.23 * *$ & $-0.24 * *$ & $-0.20 * *$ \\
\hline & $(0.04)$ & $(0.05)$ & $(0.07)$ & $(0.02)$ \\
\hline \multirow[t]{2}{*}{ ESCB membership } & $-0.15^{* *}$ & $-0.15^{* *}$ & $-0.12 * *$ & $-0.13 * *$ \\
\hline & $(0.04)$ & $(0.04)$ & $(0.03)$ & $(0.03)$ \\
\hline \multirow[t]{2}{*}{ Quality of government } & 0.02 & 0.02 & $0.04 * *$ & $0.05^{*}$ \\
\hline & $(0.03)$ & $(0.03)$ & $(0.01)$ & $(0.03)$ \\
\hline \multirow{2}{*}{$\begin{array}{l}\text { CBI reforms in economic } \\
\text { cooperation }\end{array}$} & -0.02 & -0.02 & $-0.02 *$ & $-0.02 *$ \\
\hline & $(0.01)$ & $(0.01)$ & $(0.01)$ & $(0.01)$ \\
\hline \multirow[t]{2}{*}{ Power distance } & - & -0.08 & 0.03 & 0.09 \\
\hline & & $(0.11)$ & $(0.15)$ & $(0.12)$ \\
\hline \multirow[t]{2}{*}{ Uncertainty avoidance } & - & - & $-0.32 * *$ & $-0.33 * *$ \\
\hline & & & $(0.01)$ & $(0.09)$ \\
\hline \multirow[t]{2}{*}{ Masculinity } & - & - & - & $-0.38 * *$ \\
\hline & & & & $(0.01)$ \\
\hline \multirow[t]{2}{*}{ Constant } & $3.45^{* *}$ & $3.53 * *$ & $3.70 * *$ & $3.87 * *$ \\
\hline & $(0.32)$ & $(0.20)$ & $(0.25)$ & $(0.35)$ \\
\hline Log-likelihood & -63.33 & -63.27 & -62.27 & -60.62 \\
\hline Likelihood ratio - Chi-2 (13) & 52.97 & 53.10 & 55.08 & 58.39 \\
\hline AIC & 127.07 & 126.94 & 124.95 & 121.65 \\
\hline Observations & 149 & 149 & 149 & 149 \\
\hline Imputation method & Multiple & Multiple & Multiple & Multiple \\
\hline Model & ACF & $\mathrm{ACF}$ & $\mathrm{ACF}$ & $\mathrm{ACF}$ \\
\hline Distribution & $\begin{array}{l}\text { Generalized } \\
\text { gamma }\end{array}$ & $\begin{array}{l}\text { Generalized } \\
\text { gamma }\end{array}$ & $\begin{array}{l}\text { Generalized } \\
\text { gamma }\end{array}$ & $\begin{array}{l}\text { Generalized } \\
\text { gamma }\end{array}$ \\
\hline
\end{tabular}

Notes: The table report results for regression models with the number of years from 1980 until CBI reform as the dependent variable. The explanatory variables are the average of the values for the ten-year period preceding CBI reforms (different time periods in different countries). *significant at the $10 \%$ level, ** significant at the $5 \%$ level. 
Table 4. Duration analysis of determinants of time until implementation of CBI reform - non-linear trust.

\begin{tabular}{|c|c|c|c|c|c|c|}
\hline & Model 5 & Model 6 & $\begin{array}{c}\text { Model } 7 \\
\text { (Democracies) }\end{array}$ & $\begin{array}{c}\text { Model } 8 \\
\text { (Autocracies) }\end{array}$ & Model 9 & Model 10 \\
\hline Social trust & $\begin{array}{c}0.84 \\
(0.58)\end{array}$ & - & - & - & $\begin{array}{l}1.55^{* *} \\
(0.06)\end{array}$ & - \\
\hline Social trust ${ }^{2}$ & $\begin{array}{c}-2.15^{* *} \\
(1.02)\end{array}$ & - & - & - & $\begin{array}{c}-2.44 * * \\
(0.41)\end{array}$ & - \\
\hline \multicolumn{7}{|l|}{ Restricted cubic spline } \\
\hline Social trust - spline 1 & - & $\begin{array}{c}0.85 * * \\
(0.20)\end{array}$ & $\begin{array}{c}0.50 * * \\
(0.17)\end{array}$ & $\begin{array}{c}3.72 * * \\
(0.13)\end{array}$ & - & $\begin{array}{c}2.05^{* *} \\
(0.11)\end{array}$ \\
\hline Social trust - spline 2 & - & $\begin{array}{c}-2.29 * * \\
(0.38)\end{array}$ & $\begin{array}{c}-1.87 * * \\
(0.88)\end{array}$ & $\begin{array}{c}-5.299 * * \\
(0.52)\end{array}$ & - & $\begin{array}{c}-2.83 * * \\
(0.33)\end{array}$ \\
\hline $\begin{array}{l}\text { Explanatory variables (as in } \\
\text { model 4) }\end{array}$ & Yes & Yes & Yes & Yes & Yes & Yes \\
\hline Log-likelihood & -59.65 & -58.386 & -22.40 & -19.25 & -60.25 & -53.35 \\
\hline $\begin{array}{l}\text { Likelihood ratio - Chi-2 } \\
\text { (13) }\end{array}$ & 60.328 & 61.73 & 43.60 & 39.42 & 61.72 & 75.53 \\
\hline AIC & 119.70 & 118.30 & 45.20 & 38.90 & 122.50 & 110.70 \\
\hline Observations & 149 & 149 & 89 & 60 & 149 & 149 \\
\hline Imputation method & Multiple & Multiple & Multiple & Multiple & Mean & Mean \\
\hline Model & ACF & ACF & ACF & ACF & $\mathrm{ACF}$ & ACF \\
\hline Distribution & $\begin{array}{l}\text { Generalized } \\
\text { gamma }\end{array}$ & $\begin{array}{l}\text { Generalized } \\
\text { gamma }\end{array}$ & Log-normal & Log-normal & Log-normal & Log-normal \\
\hline
\end{tabular}

Notes: The table report results for regression models with the number of years from 1980 until CBI reform as the dependent variable. The explanatory variables are the average of the values for the ten-year period preceding CBI reforms (different time periods in different countries). *significant at the $10 \%$ level, **significant at the $5 \%$ level. The models based on the generalized gamma distribution did not converge when separating between democracies and autocracies due to the smaller samples sizes. The results for these sub-samples are therefore based on models using the log-normal distribution. Results for other explanatory variables are similar to those previously reported for models with linear trust specifications. 

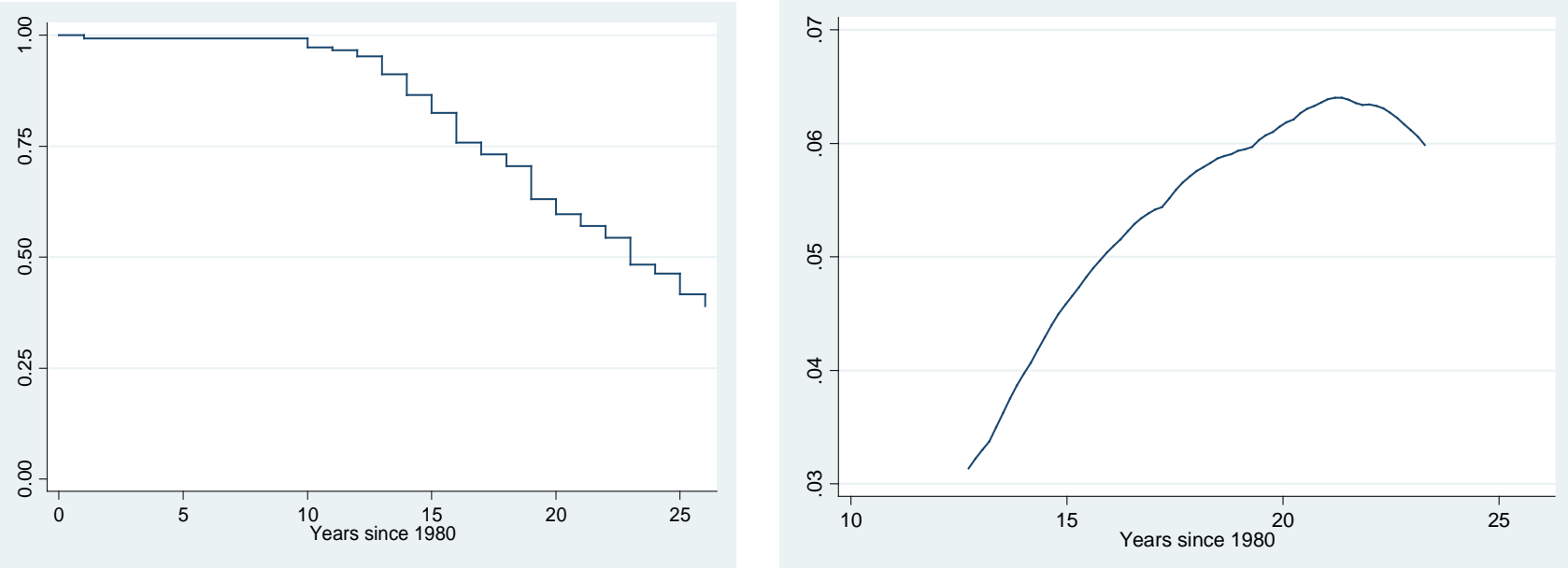

Fig. 1. Kaplan-Meier survivor (left) and smoothed hazard function (right). 


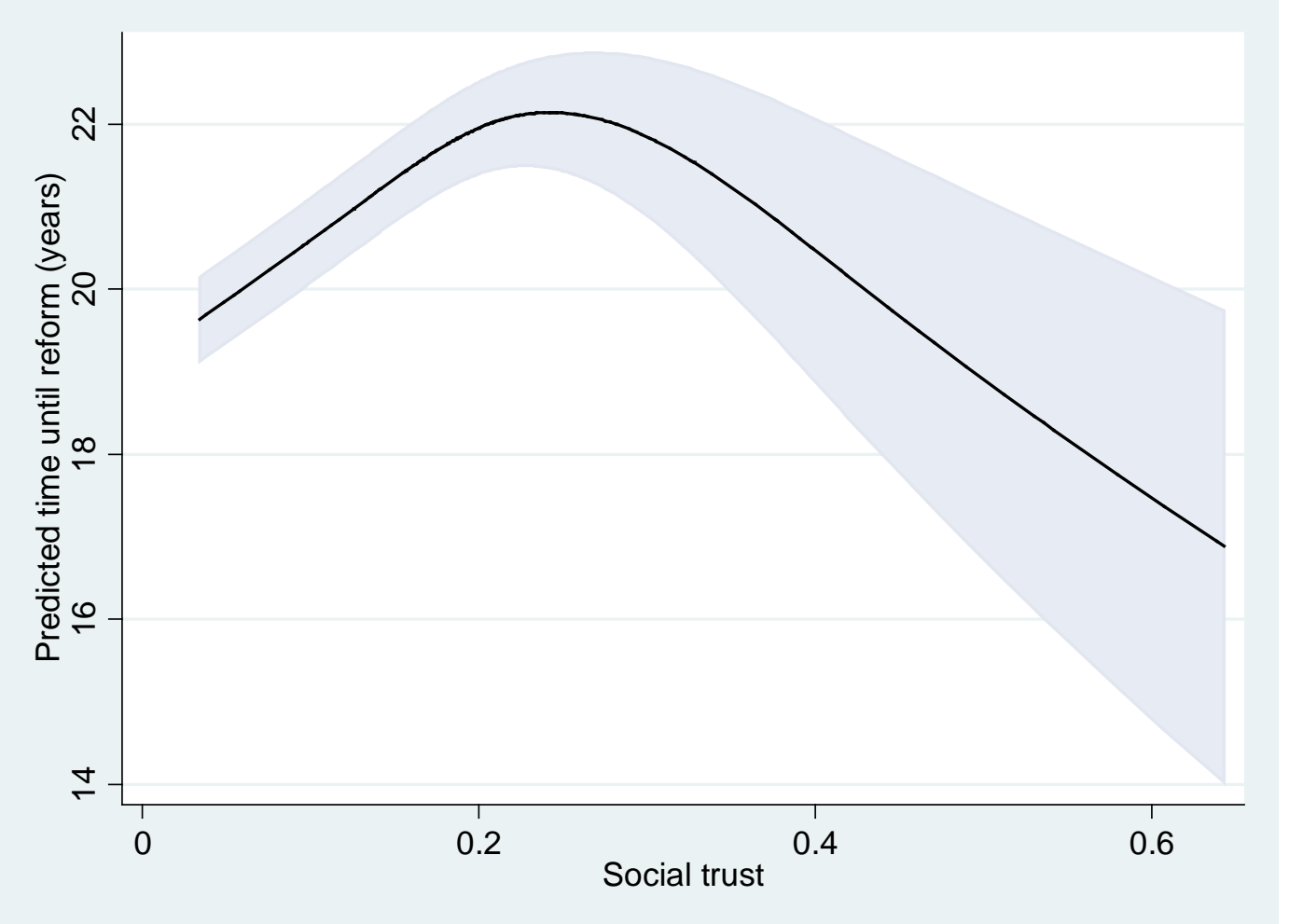

Fig. 2. Predicted time until reform (in years) depending on social trust (model 6, Table 4). 


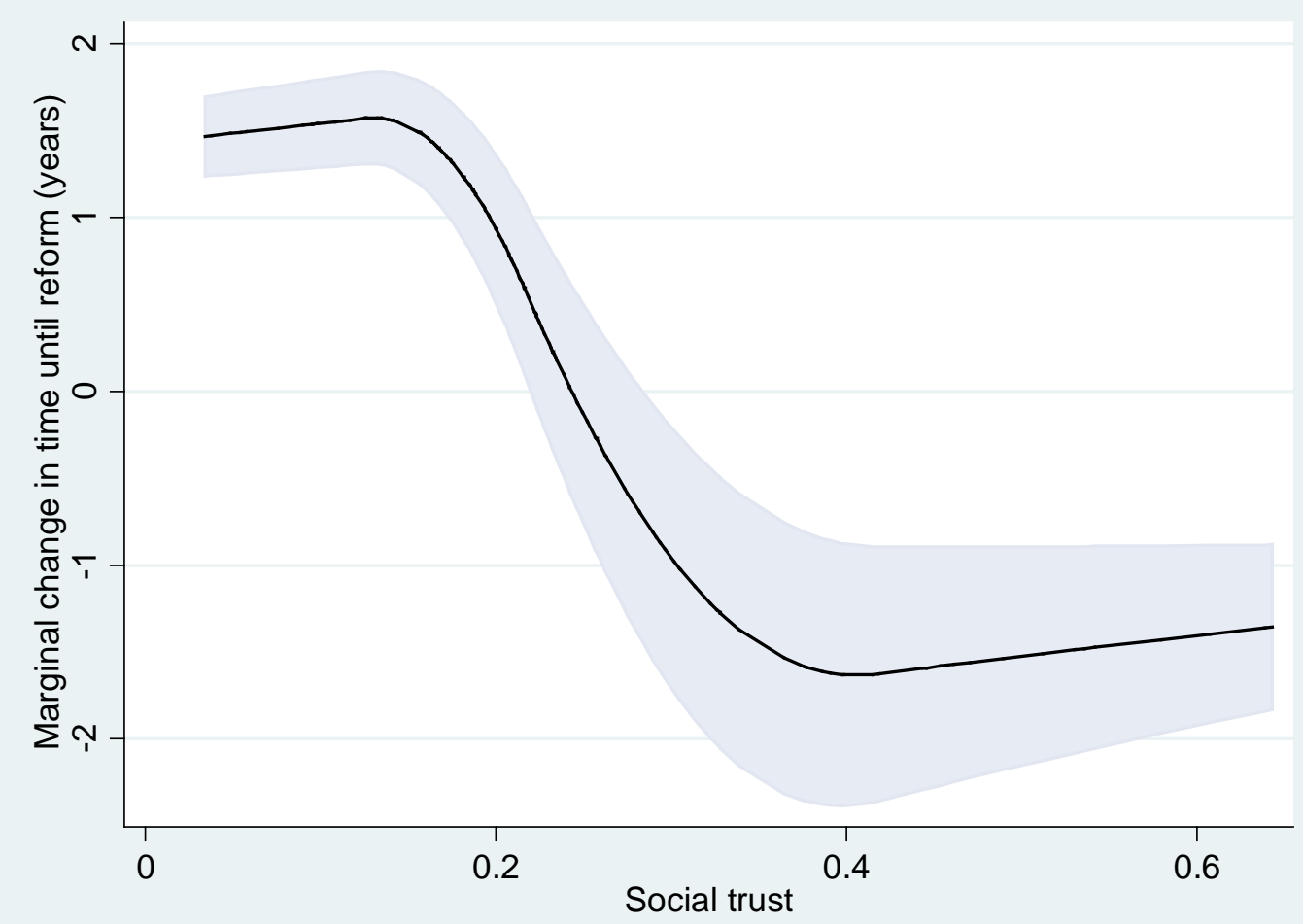

Fig. 3. Marginal effects (in years) for different levels of social trust (model 6, Table 4). 


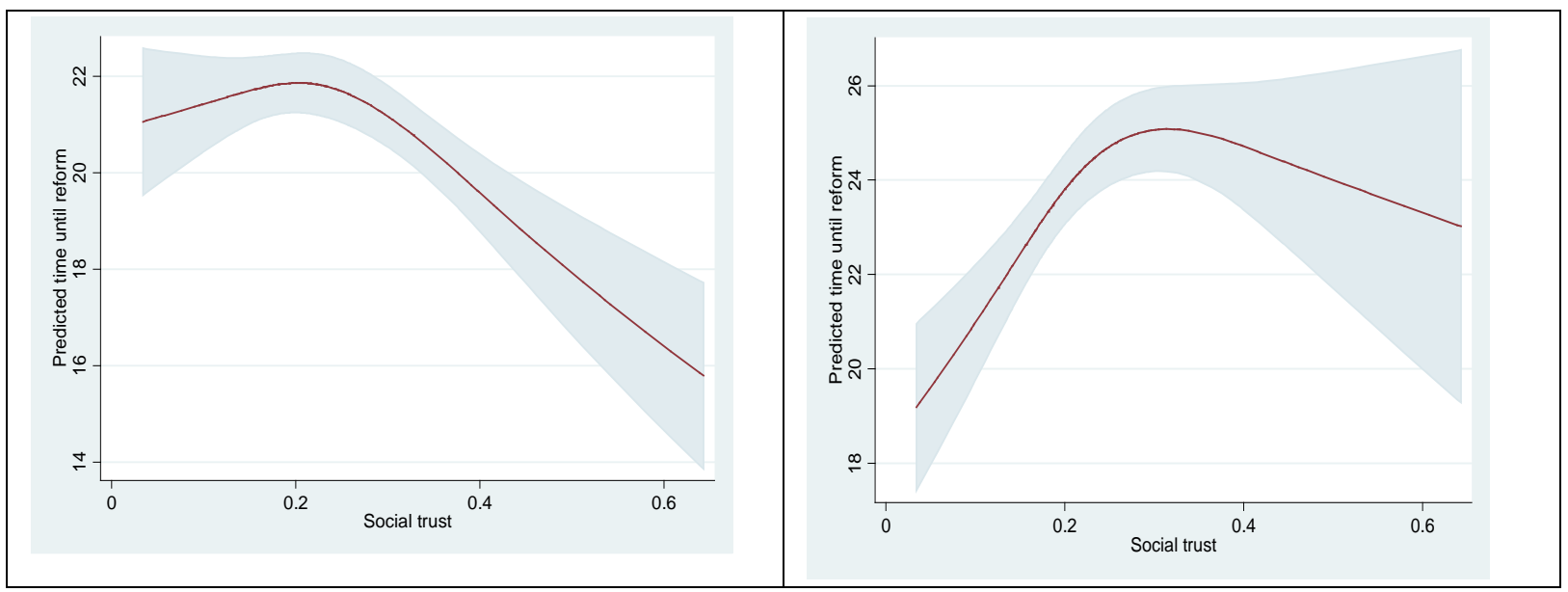

Fig. 4. Predicted time until reform (in years) for democracies (left) and non-democracies (right) based on models 7 and 8, Table 4.
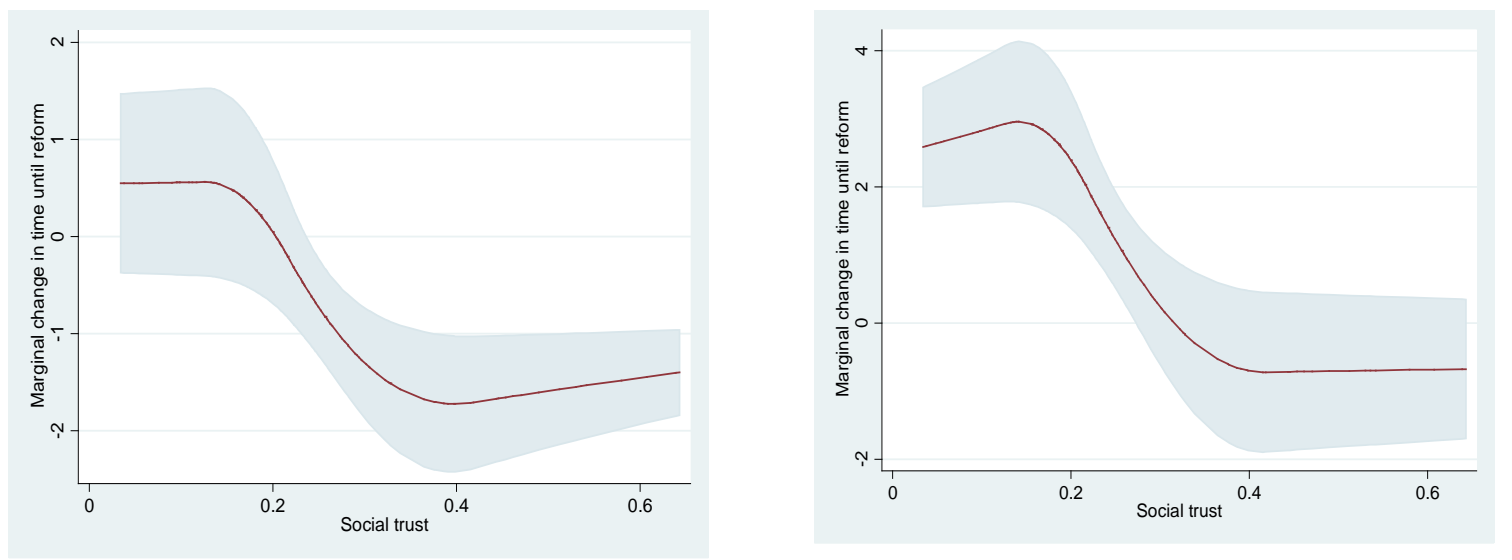

Fig. 5. Marginal effects (in years) for democracies (left) and non-democracies (right) based on models 7 and 8 , Table 4. 